\title{
A QUESTÃO DA ALTERIDADE NA RECEPÇÃO LEVINASIANA DE HEIDEGGER
}

Paulo Cesar Duque-Estrada*

SÍNTESE - Pretende-se situar os momentos determinantes que dão sustentação à proposta de Levinas, elaborada ao longo de sua leitura de Heidegger, no sentido de romper com o pensamento do ser e propor um pensamento do Outro. A leitura de Levinas, como se pretende demonstrar, é atravessada, desde o seu início, pelo fio condutor de uma problematização da pretendida abertura para fora de si mesmo, na qual o Dasein heideggeriano quer se afirmar para além de toda autoconfirmação inerente às filosofias da consciência. PALAVRAS-CHAVE - Alteridade. Dasein. Heidegger. Levinas.
ABSTRACT - This article seeks to situate the decisive moments that support Levinas's proposal, elaborated throughout his reading of Heidegger, insofar as it breaks away from the thought of Being and proposes a thought of the Other. Levinas's reading, it is argued, is marked from the beginning by the leading motif of a problematization of the supposed openness out of itself, in which the Heideggerian Dasein claims to affirm itself beyond all self-confirmation inherent in philosophies of consciousness.

KEY WORDS - Alterity. Dasein. Heidegger. Levinas.

Escrever sobre Levinas sempre me pareceu uma tarefa muito difícil. Muito difícil, inicialmente, porque eu não conseguia me certificar, na leitura de seus textos, se eu havia, de fato, me dado conta ou conseguido me situar na tal abertura para além do ser, para além de toda inteligibilidade, que ele nos convida a pensar. Ocorria-me, com freqüência, a suspeita de que eu me encontrava transitando, pelos textos de Levinas, seguindo linhas muito equivocadas de interpretação que acabavam por associar a sua escrita àquilo que ele mesmo, certa vez, chamou de "fraqueza do espírito"; ou seja, "a simples [entenda-se, ingênua ou dogmática] coexistência da filosofia e da religião nas almas e até nas civilizações". ${ }^{1}$ Contudo, uma vez conquistada uma certa familiaridade com os seus textos, a dificuldade de escrever sobre Levinas sobreveio, então, de um outro modo; na forma de uma intimidação. Mais especificamente, uma intimidação que se experimenta quando se começa a perceber a beleza, o refinamento e a delicadeza de uma coerência de pensamento à qual se pretende tratar com justeza, em uma leitura capaz de lhe render justiça.

* PUC-Rio

Cf. Levinas, E.: "O Vestígio do Outro."; in Descobrindo a Existência com Husserl e Heidegger. Instituto Piaget. Lisboa., p. 231.

\begin{tabular}{|l|l|l|l|l|l|}
\hline VERITAS & Porto Alegre & v. 51 & n. 2 & Junho 2006 & p. 29-35 \\
\hline
\end{tabular}


Tal coerência, é importante que se diga, não se reduz a um simples rigor no encadeamento das razões que dão corpo à sua argumentação. Antes, ou mais do que isso, trata-se da coerência de um pensador que, enquanto filósofo, soube não se perder, mesmo tendo a sua vida tragicamente atravessada por fatores adversos fora e dentro da filosofia: como se sabe, o jovem imigrante lituano, judeu, residindo na França, vai para a Alemanha, em 1928, estudar com os mestres da fenomenologia, Husserl e Heidegger. Este último já era conhecido na ocasião, como o autor de Ser e Tempo, livro publicado um ano antes, que provocara um profundo abalo na fenomenologia e que provocaria, igualmente, um profundo impacto na vida e na obra futura do então jovem estudante. Nesta mesma Alemanha, anos mais tarde, Levinas será preso em um campo para soldados franceses, numa guerra que em, sua terra natal, não deixará um único parente seu vivo. Já na época em que transcorrem esses trágicos eventos e, após a guerra, de volta à França, por um período praticamente de três décadas, Levinas, de um modo ou de outro, não cessará de se reportar a Heidegger. Mas não com o intuito de invalidar a sua obra à luz do que aconteceu, o que seria de um simplismo de todo incompatível com o seu pensamento. E sim por entender que a ontologia heideggeriana - justo pelo seu poder não só de abalar os alicerces da metafísica, como também de abrir novas possibilidades para o questionamento filosófico - constituia um "lugar" privilegiado para se pensar toda uma racionalidade que, a seu ver, por comportar um certo fechamento estrutural a ela própria, sempre abrigou a possibilidade de consentir com o Mal. Ou, para usarmos uma expressão do próprio Levinas, uma racionalidade que sempre comportou a possibilidade de se afirmar "como um consentimento com o horrível". .

Será, portanto, neste sentido, levando em conta este duplo aspecto implicado em sua obra; ou seja, por um lado, os trágicos acontecimentos que marcaram a sua vida, e, por outro lado, a coerência de seu pensamento, que lhe permitiu resistir às investidas aniquiladoras de seu tempo, desdobrando-se para além do ressentimento, do espírito de vingança e das inevitáveis tentações simplistas ou dogmáticas; é, enfim, neste sentido que tentarei situar alguns elementos determinantes da leitura levinasiana do pensamento de Heidegger. Nesta leitura, marcada por um movimento simultâneo de aproximação e afastamento, de recepção e resistência, de herança e deserção, o pensamento de Levinas irá romper com a ontologia, entendida como "pensamento do mesmo", para se afirmar como uma ética, entendida como "pensamento do outro".

$$
* * *
$$

Este movimento paradoxal, ambíguo, de sua relação com Heidegger, pode, de fato, ser detectado desde muito cedo na produção intelectual de Levinas. Exemplo

Comme um consentement à l'horrible é o título de um artigo de Levinas escrito para o Le Nouvel Observateur, publicado em janeiro de 1988, por ocasião do ressurgimento, a partir do livro de Vitor Farias, das discussões sobre o envolvimento de Heidegger com o nazismo. Devo a Ricardo Timm de Souza o acesso ao referido artigo de Levinas. 
disto é o texto "A ontologia no temporal", ${ }^{3}$ de 1940, que, embora dedicado a uma apresentação das teses centrais de Ser e Tempo, o que, aliás, é feito de um modo brilhante, já comporta indicações de uma tomada de posição crítica em relação a Heidegger. ${ }^{4}$ Posição esta que, no entanto, só irá se desenvolver plenamente anos mais tarde. As palavras finais deste texto de Levinas não deixam dúvida quanto a isto:

[...] a ontologia de Heidegger dá os acordes mais trágicos e torna-se o testemunho de uma época e de um mundo que talvez amanhã seja possível ultrapassar.

Mas, para um texto que termina com tais palavras, o que haveria no pensamento de Heidegger que merecesse uma apresentação tão cuidadosa e paciente por parte de Levinas?

Dentre a enorme variedade de temas que se abre em Ser e Tempo, Levinas localiza um deles como o horizonte comum que organiza todos os outros: a compreensão (Verstehen). Segundo Levinas, a noção de compreensão seria o agente de toda a filosofia heideggeriana desenvolvida em Ser e Tempo. Como se sabe, Heidegger sustenta que, dentre todos os entes, o homem é um ente especial que se caracteriza por compreender o modo de ser de todos os entes, inclusive o seu próprio modo de ser. Isto significa que, em sua relação com o que quer que seja, não apenas o modo de ser daquilo com o que ele se relaciona, mas também o seu próprio modo de ser, já foi, de alguma forma, previamente dado numa compreensão. O alcance crítico de uma tal colocação não passou desapercebido por Levinas. Referindo-se ao tema da compreensão do ser no pensamento de Heidegger, ele diz o seguinte:

Quando ele [Heidegger] a põe [a compreensão do ser] como pano de fundo de todas as nossas relações com o real, ele quer dizer mais do que o idealismo que reduz o real às nossas representações. ${ }^{5}$

A motivação de Levinas, no fundo desta sua observação, está em pensar a possibilidade de um pensamento que seja capaz de pensar para além de uma razão autista, que reduz tudo a si mesma. No caso da referência ao idealismo, na passagem citada, trata-se de uma redução de todas as coisas ao "si" da consciência que representa. Pensar, aqui, se reduz a uma questão de saber como proceder para que tudo possa ser trazido de volta e, portanto, ser devidamente organizado, estruturado, fundamentado, a partir da consciência que se dá a si mesma. Tratase, em outros termos, de um pensamento que reduz tudo à ordem do mesmo; isto é, à ordem de uma razão impessoal, abstrata, neutra, indiferente e, nessas condições, universal. E Levinas não deixa de perceber em Heidegger um movimento em direção ao rompimento com uma tal redução à ordem do mesmo. Vejamos como.

In Levinas, E: Descobrindo a Existência com Husserl e Heidegger. Ed. Instituto Piaget. Lisboa. Devo esta constatação a Jacques Taminiaux, em seu artigo "The early Levinas's reply to Heidegger's fundamental ontology"; in Philosophy \& Social Criticism - vol. 23 n. 6. 1997.

A ontologia no temporal, p. 98. 
É que estando sempre e já pressuposta em qualquer relação entre sujeito e objeto, a compreensão do ser, como precisa Levinas, se constitui como uma espécie de esboço através do qual acedemos tanto ao objeto quanto ao sujeito; ou, em outras palavras, tanto ao objeto representado quanto à representação do objeto. Assim, o que é compreendido ali, na compreensão do ser de um ou de outro, do objeto representado ou da representação do objeto, não é, por sua vez, um outro objeto ou uma outra coisa. Não se trata, como diz Levinas, de "um conteúdo qualquer mais vago que as coisas, ou abstraído de várias coisas...". Numa palavra, o que é compreendido é "aquilo" em função do qual uma coisa é o que ela é, ou seja, o seu ser.

Tendo em vista a questão que interessa a Levinas, qual seja, a de viabilizar um pensamento capaz de pensar ou de fazer justiça à alteridade, pode-se dizer que o tema heideggeriano da compreensão do ser apresenta, pelo menos, dois aspectos importantes:

1) Todas as estratégias e procedimentos redutores do pensamento sofrem, com este tema da compreensão, um forte abalo. E isto na medida em que, para toda e qualquer instância estabelecida como o pano de fundo ou o elemento organizador do aparecer das coisas; portanto, como o horizonte para onde deve convergir a redução de todas as coisas, coloca-se, imediatamente, a questão sobre o modo de ser de tal horizonte. Assim, por exemplo, se o campo transcendental é o horizonte que torna possível a visibilidade dos objetos, coloca-se a questão sobre o horizonte que torna possível a visibilidade ou o acesso ao próprio campo transcendental, ou seja, o seu modo de ser enquanto tal.

2) Antes de qualquer formulação teórica, a compreensão do ser é algo que diz respeito direta e imediatamente a todos; todos os que se encontram inscritos no horizonte da humanidade. Portanto, a todos nós, humanos. Nas palavras de um Levinas ainda mais jovem e, ao que parece, mais entusiasmado com o pensamento heideggeriano, em seu texto "Martin Heidegger e a ontologia", de 1932: "a compreensão do ser é a característica e o fato fundamental da existência humana." Neste sentido, podemos precisar, ainda acompanhando Levinas, que ela, a compreensão do ser, caracteriza o homem, mas, de forma alguma, "como atributo essencial, [e sim] como o próprio modo de ser do homem." Numa palavra, a compreensão do ser "não determina a essência, mas a existência do homem."

Seria necessário um longo desvio para situarmos aqui, satisfatoriamente, a argumentação de Heidegger segundo a qual a compreensão do ser caracteriza fundamentalmente o homem, mas não como atributo essencial, não como essência, e sim como existência. O próprio Levinas, contudo, nos poupa deste enorme trabalho, oferecendo uma síntese precisa do que está em jogo neste argumento:

Lévinas, E: "Martin Heidegger e a Ontologia"; in Descobrindo a Existência com Husserl e Heidegger, p. 74. Em itálico no original.

Ibid; p. 75. 
Certamente, se considerarmos o homem como um ente, a compreensão do ser constitui a essência desse ente. Mas precisamente - e aí está uma característica fundamental da filosofia heideggeriana - a essência do homem é, ao mesmo tempo, a sua existência. Aquilo que o homem é, é ao mesmo tempo a sua maneira de ser, a sua maneira de existir, de se "temporalizar'.," [...] Em resumo [diz Levinas, mais adiante], ser para o Dasein [esse ser-aí que somos nós], é compreender o ser. ${ }^{9}$

Acrescentaríamos apenas, reforçando com outras palavras a síntese de Levinas, algo que se torna mais claro nos textos de Heidegger posteriores a Ser e Tempo: a maneira de ser ou de existir do homem consiste, fundamentalmente, na sua maneira de encontrar-se aberto ou exposto ao ser; somos todos, nós, seres humanos, fundamentalmente este estar-aí aberto ou exposto ao ser. O tema da compreensão do ser, em Ser e Tempo, tenta trazer à luz esta condição fundamental da existência humana.

A princípio, esta argumentação heideggeriana poderia significar, para Levinas, a tão esperada ruptura com o pensamento do mesmo: não só a alteridade do ser significaria uma quebra na imanência da razão, já que o ser antecipa e, portanto, escapa sempre à generalidade dos conceitos, como também o homem, mostrando-se indissociavelmente - ou essencialmente - ligado à esta alteridade irredutível do ser, estaria, portanto, igualmente a salvo das investidas redutoras da razão. Mais ainda, sendo a verdade entendida, em Heidegger, como desvelamento do ser, a existência humana mostrar-se-ia, neste sentido, não apenas à salvo da ordem do mesmo, como também, dada a sua íntima associação ao ser, uma parte integrante e indiscernível da verdade mesma enquanto desvelamento. E, de fato, no texto de 1932, Levinas se refere a toda essa argumentação de Heidegger nos seguintes termos:

[...] [que a] transformação do ser em verdade se cumpra no fato da minha existência particular neste mundo, que o meu lugar, o meu Da [o meu aí; do estar-aí no mundo] seja produto da revelação do ser, que a minha humanidade seja a verdade - isso constitui o principal contributo do pensamento heideggeriano. A essência do homem está nessa obra de verdade; o homem não é, pois, um substantivo, mas um verbo inicialmente: ele está na economia do ser, o 'revelar-se' do ser, ele não é Daseiendes [um "ente deste mundo"], mas Dasein [um "ser deste mundo"].

No entanto, o entusiasmo de Levinas não cessa de dar lugar a um movimento contrário; não esqueçamos das últimas palavras de "A Ontologia no Temporal", escrito oito anos mais tarde:

[...] a ontologia de Heidegger dá os acordes mais trágicos e torna-se o testemunho de uma época e de um mundo que talvez amanhã seja possível ultrapassar.

Não é possível seguir aqui todos os aspectos inerentes à esta mudança de tom na relação com Heidegger. Portanto, para ganhar tempo, cito a seguinte frase, de um texto de 1963, "O Rastro do Outro":

Ibid.

Ibid., p. 84. 
[...] o ser na verdade não altera a identidade do Eu. ${ }^{10}$

A princípio - acompanhando Levinas, que acompanhava Heidegger -, o idealismo da consciência parecia ter encontrado o seu limite, a sua quebra, na alteridade do ser. Agora, por contraste - e, aliás, em um texto cujo título já não traz mais palavras como "ser" e "ontologia", mas sim "rastro" e "outro" -, Levinas afirma, que a estrutura auto-identitária, redutora ao "si", à ordem do mesmo, não se rompe mas, ao contrário, segue inabalável com o pensamento do ser. O caminho de Levinas aqui já não se orienta mais pela retomada da questão do ser. E esta mudança já não significa apenas um desvio, um deslocamento ou simples variação, dentro de uma mesma orientação, ou de um mesmo ambiente de pensamento. Ao contrário, tal mudança traz agora os traços de uma rejeição:

A filosofia ocidental coincide com a revelação do Outro onde o Outro, ao manifestar-se (...), perde a sua alteridade. A filosofia foi desde sempre atingida por um horror ao Outro que continua a ser Outro, por uma alergia insuperável. É por isso que ela é essencialmente uma filosofia do ser, que a compreensão do ser é a sua última palavra e a estrutura fundamental do homem. ${ }^{11}$

Agora, aos olhos de Levinas, fica claro que, se a singularidade do Outro não é revelada pelo conceito, mas, antes, apropriada e apagada pela sua generalidade - uma generalidade abstrata, indiferente à singularidade de que ela se apropria -, o mesmo ocorre também com o pensamento do ser. Deste modo, pensar, com Heidegger, que a existência humana se caracteriza pela compreensão do ser, significa que, com tal pensamento, já deixamos para trás, já demos as costas, para o existente; mais precisamente, para a eterna singularidade do que é não a existência mas um existente. Mas é isto o que, em Heidegger, significa a autenticidade: assumir o seu ser mais próprio, a autêntica relação consigo mesmo, é assumir, em meio aos entes mas, ao mesmo tempo, para além de todo comércio com os entes, o que fundamentalmente somos: abertura ao ser e, portanto, potencialidade-de-ser. A ontologia pretende ser, neste sentido, a máxima realização do que nós, seres humanos, somos; afinal, ela trata daquilo que, da maneira mais fundamental, mais decisiva, está em jogo em todo o nosso estar-aí-no-mundo; ou seja, não isto ou aquilo, nada que exista, nenhum ente, real ou de qualquer outra ordem, mas, precisamente, o que não é ente algum; o ser.

Neste sentido, se o nada do ser - já que o ser não é ente algum -, e, por extensão, o nada que nós somos - já que nossa existência repousa, fundamentalmente, em um ter-de-ser, em uma potencialidade-de-ser, e nada mais -; se este nada dissolve a pretensa segurança do que quer que se afirme como fundamento, isto não impede que a mesma estrutura ou que o mesmo processo de redução ao fundamento siga implacável; mesmo quando não há mais fundamento algum, mas, antes, o nada do ser. Ainda assim, Levinas percebe a persistência de uma redução de tudo a um mesmo. Um mesmo que, agora, se põe como o nada da existência, e que Levinas sintetiza do seguinte modo:

${ }_{11}^{10}$ In: Descobrindo a Existência ..., p. 228.

Ibid., p. 229. 
[a filosofia de Heidegger] descobre o nada em que assenta, o que significa também que não assenta em nada que não seja ela própria. ${ }^{12}$

E ela própria, a filosofia de Heidegger, repitimos, constitui a mais própria realização da existência humana enquanto ser-(ou-estar)-aí-no-mundo.

Tentando buscar um caminho alternativo ao pensamento heideggeriano, Levinas coloca, então, a seguinte pergunta: "Existirá alguma significação que não seja equivalente à transmutação do Outro no Mesmo?"13

Em sua resposta afirmativa, ele reconhece, por um lado, que o Outro sempre aparece, inevitavelmente, em uma certa conformidade com alguma totalidade em que ele se insere. O Outro, diz Levinas, sempre "está presente num conjunto cultural e esclarece-se por meio deste conjunto, como um texto pelo seu contexto."14 Mas, por outro lado,

[o Outro] comporta um significado próprio independente desse significado recebido do mundo. Outrem [como ele chama aqui o Outro] não nos vem apenas a partir do contexto, mas sem mediação, significa por si mesmo. ${ }^{15}$

Este vir até nós, esta visitação, como ele diz, imediata, surpreendente, do Outro é o que Levinas chama de rosto. Mas não é por uma qualquer espécie de exuberância, envolto numa roupagem polissêmica, que o rosto nos visita. Ao contrário, a sua visitação se dá, para além de todo trabalho hermenêutico ou exegético, como uma "intimação para responder." Neste encontro com o Outro, o Eu se acha naquilo que, de fato, segundo Levinas, o unifica enquanto tal; ou seja, no fato de que ninguém pode, em seu lugar, responder ... não ao ser, mas à singularidade do Outro.

\footnotetext{
A Ontologia no Temporal, p. 111

O Rastro do Outro, p. 231.

Ibid., p. 235

Ibid., p. 235
} 